\title{
Comparison of the Effect of Skin Preparation Pads on Transepidermal Water Loss in Ex Vivo Human Skin
}

\author{
Hanan Osman-Ponchet - Alexandre Gaborit • Magali Kouidhi • \\ Sandrine Anglars · Jeanne Marceau-Suissa - Orla Duffy-Roger • \\ Jean-Michel Linget · Claire E. Wilson
}

Received: April 26, 2017 / Published online: July 14, 2017

(C) The Author(s) 2017. This article is an open access publication

\begin{abstract}
Introduction: Pre-treatment of the skin to remove scales and crusts prior to photodynamic therapy (PDT) is essential to enhance the uptake of topically applied methyl aminolevulinate (MAL) and to improve treatment efficacy. This study compared the effect of two different skin preparation pads on skin integrity in ex vivo human skin.

Methods: Ex vivo human skin samples from three donors were pre-treated in triplicates with PREPSTER $^{\mathrm{TM}}$ (PR) skin preparation pad $(6,8$, and 10 passages) or Ambu Unilect ${ }^{\mathrm{TM}}$ (A-UN) skin preparation pad $(6,8$, and 10 passages). In addition, skin samples were pre-treated with tape strippings ( 10 adhesive tape strips) as a reference method for comparison. Transepidermal water loss (TEWL) was measured on intact skin and following skin barrier impairment using skin preparation pads and tape stripping. Histological analysis was performed to verify the impairment of the stratum corneum (SC) barrier function in samples from intact skin
\end{abstract}

Enhanced content To view enhanced content for this article go to www.medengine.com/Redeem/ DFD8F0607925BFDB.

H. Osman-Ponchet $(\bowtie) \cdot A$. Gaborit · M. Kouidhi · S. Anglars · J. Marceau-Suissa · O. Duffy-Roger · Jean-MichelLinget · C. E. Wilson

Nestlé Skin Health - Galderma R\&D, Sophia

Antipolis, France

e-mail: hanan.osman-ponchet@galderma.com (control), 10 tape strippings (reference method), 10 passages of PR, and 10 passages of A-UN.

Results: TEWL increased with the increasing number of passages of skin preparation pads, with 2.4- and 3.3-fold increases following 10 passages of A-UN and PR, respectively, versus a 2.2-fold increase with 10 tape strippings (reference). Histological analysis showed only partial removal of the SC, with no damage observed on the epidermis, regardless of the procedure used. Conclusion: Pre-treatment of skin using PR and A-UN skin preparation pads markedly increases TEWL, indicating slight impairment of the SC barrier function. Comparison of both skin preparation pads showed that PR pad consistently induced significantly higher TEWL than A-UN pad $(p<0.05)$, regardless of the number of passages. Both skin preparation pads are thought to increase the uptake of MAL and can therefore be used for the preparation of skin prior to PDT.

Funding: Nestlé Skin Health - Galderma R\&D.

Keywords: Ex vivo human skin; Skin preparation pad; Tape stripping; Transepidermal water loss

\section{INTRODUCTION}

Conventional photodynamic therapy (PDT) and more recently daylight-mediated PDT with 
methyl aminolevulinate (MAL) cream (Metvix ${ }^{\circledR}$; Galderma, Switzerland) are efficacious for the treatment of actinic keratosis (AK) [1, 2]. Pre-treatment of the skin to remove scales and crusts prior to PDT is recommended by European PDT guidelines [3]. Indeed, pre-treatment of skin overcomes the barrier function of the stratum corneum (SC), which prevents the delivery of MAL across the skin. Consequently, pre-treatment enhances the uptake of topically applied MAL, thus improving treatment efficacy $[4,5]$.

Curettage is the recommended pre-treatment procedure due to its efficacy and ease of use [6-9]. However, numerous alternative procedures for the preparation of skin prior to PDT, to overcome SC barrier properties, are emerging. These include pre-treatment using salicylic acid or urea as a chemical keratolytic procedure, microneedling, ablative and non-ablative fractional lasers, and abrasion with skin preparation pads as a mechanical procedure for skin preparation [10-13]. However, thus far, only a very few studies have assessed the effectiveness of skin preparation pads in enhancing the uptake of MAL for the treatment of AK [14].

Tape stripping is a common mechanical method used for the disruption of skin $[15,16]$. First described by Fritsch et al. [17], tape stripping involves the disruption of the superficial layers of the SC by placing and pressing adhesive tape onto the skin surface followed by removal of the tape. Repeated tape stripping has been used as an effective comparative model for impaired skin barrier function to improve the penetration of xenobiotics. Indeed, impairment of SC barrier properties is associated with an increase in the penetration of topically applied drugs, such as penciclovir and aciclovir. Disruption of the SC by tape stripping increased penciclovir and aciclovir absorption by 1300-fold and 440-fold, respectively. These findings confirm the role of the SC as the major barrier to hydrophilic drug absorption [18].

SC barrier impairment is quantified by measuring transepidermal water loss (TEWL) expressed in grams per square meter per hour $\left(\mathrm{g} / \mathrm{m}^{2} / \mathrm{h}\right)$. TEWL is a well-established parameter for the determination of skin integrity and skin barrier function in humans [19], and tape stripping leads to increased TEWL [20]. Data have shown a close correlation between penciclovir concentration absorbed per hour and barrier disruption, measured by TEWL following sequential barrier disruption with tape stripping [18]. Moreover, numerous studies have suggested that high TEWL is associated with various skin diseases including atopic dermatitis, psoriasis, contact dermatitis, and ichthyosis [21-23].

The objective of this study was to compare the effect of two different skin preparation pads, used for the preparation of skin prior to PDT to enhance the uptake of MAL during AK treatment, on skin integrity using ex vivo human skin. TEWL was used to compare skin barrier function in intact skin and in compromised skin after several passages of skin preparation pad, or after repeated tape stripping (used as reference).

\section{METHODS}

\section{Skin Sample Preparation}

Human skin samples were obtained in agreement with ethical and legal regulations for the use of biological material of human origin applicable in France and were approved by an internal ethics committee. Samples were derived from three different female donors (abdominal aesthetic surgeries). Thawed skin samples were cut into $3-\mathrm{cm}^{2}$ square sections. Disruption of the skin barrier was performed using a 19-mm-wide adhesive tape Scotch ${ }^{\circledR}$ transparent tape 550 (3M, France), or two different types of skin preparation pads: PREPSTER $^{\mathrm{TM}}$ (USA) (PR) and Ambu Unilect ${ }^{\mathrm{TM}}$ $2121 \mathrm{M}$ (Ambu ${ }^{\circledR}$; Denmark) (A-UN).

The study included 7 treatment conditions:

- Condition 1: 10 tape strippings (reference method)

- Condition 2: 6 passages of PR

- Condition 3: 8 passages of PR

- Condition 4: 10 passages of PR

- Condition 5: 6 passages of A-UN

- Condition 6: 8 passages of A-UN

- Condition 7: 10 passages of A-UN

Each treatment condition was performed in triplicate for each of the three donors $(n=9$ replicates per condition). 


\section{Removal of Epidermis}

TEWL was measured on intact skin samples $(n=3$, one donor) and after complete mechanical removal of the epidermis to achieve the maximal TEWL value.

\section{Measurements of TEWL}

TEWL was measured on skin mounted to flow-through glass diffusion cells (LGA type) with an application surface area of $1 \mathrm{~cm}^{2}$ and a receptor compartment containing $3 \mathrm{~mL}$ of Dulbecco's phosphate-buffered saline. The receptor fluid was continuously stirred at $350 \mathrm{rpm}$ with a magnetic stirrer. The test system was thermostated with a water-circulating bath at $37^{\circ} \mathrm{C}$. TEWL measurements were performed on the skin after a minimum of a 1-h stabilization period using a Tewameter ${ }^{\circledR}$ TM 300 (Courage + Khazaka Electronic, Germany) measuring device. The TEWL results obtained are expressed in $\mathrm{g} / \mathrm{m}^{2} / \mathrm{h}$. TEWL measurements were performed on an intact skin sample and compared to the same skin sample after mechanical damage.

\section{Histological Analysis}

Skin biopsy was performed on a 54-year-old female donor for histological examination to verify barrier impairment. Biopsy samples were obtained from:

- Intact skin (control)

- Condition 1: 10 tape strippings (reference method)

- Condition 4: 10 passages of PR

- Condition 7: 10 passages of A-UN

After mechanical damage, biopsy samples were embedded in Cryomatrix ${ }^{\mathrm{TM}}$ embedding resin (Thermo Scientific, USA). Cross-sections $(6 \mu \mathrm{m})$ were cut using a cryomicrotome (Cryotome FSE, Thermo Electron, USA). Skin sections were mounted on glass microscope slides $\left(\right.$ SuperFrost $^{\circledR}$ Plus; Thermo Scientific, USA) and stained using hematoxylin and eosin. Skin sections were observed using a Nikon Eclipse 80i microscope equipped with a DS-Ri1 high-resolution camera (Nikon Instruments, USA).

\section{Statistical Analysis}

Two-way analysis of variance (ANOVA) was performed using the Excel Data Analysis ToolPak (Microsoft, USA) to compare tape strippings and skin preparation pads. Significance was declared at the 0.05 level.

\section{Compliance with Ethics Guidelines}

This article does not contain any new studies with human or animal subjects performed by any of the authors.

\section{RESULTS}

\section{Skin Characteristics}

Full-thickness abdominal skin samples, from three donors (females) aged 44-54 years, were used in this study for TEWL measurements. Skin thickness ranged between 1.2 and $2.3 \mathrm{~mm}$.

\section{Number of Skin Preparation Pad Passages Approximating the TEWL Recorded With 10 Tape Strippings}

TEWL measurements following 10 tape strippings demonstrated a 2.2-fold increase in water efflux from the compromised skin compared to unstripped skin $(9.06 \pm 0.78$ vs. $4.20 \pm 0.36 \mathrm{~g} /$ $\mathrm{m}^{2} / \mathrm{h}$, respectively) (Fig. 1 ). The difference between stripped and control unstripped skin was statistically significant $(p<0.05)$.

TEWL measurements demonstrated an increase in water efflux after 6 passages of A-UN compared to control untreated skin (2.05-fold; $7.57 \pm 0.76$ vs. $3.69 \pm 0.27 \mathrm{~g} / \mathrm{m}^{2} / \mathrm{h}$, respectively), 8 passages (2.18-fold; $7.67 \pm 0.94$ vs. $3.52 \pm 0.27 \mathrm{~g} / \mathrm{m}^{2} / \mathrm{h}$, respectively), and 10 passages (2.39-fold; $9.75 \pm 1.23 \mathrm{vs.} 4.07 \pm 0.38 \mathrm{~g} / \mathrm{m}^{2}$ / $\mathrm{h}$, respectively) (Fig. 2a). These data indicate that TEWL increased slightly with the increasing number of passages of A-UN skin preparation pad.

Comparison analysis (Fig. 2b) showed that the difference between treated skin with A-UN skin preparation pad and untreated control skin was statistically significant $(p<0.05)$, regardless 


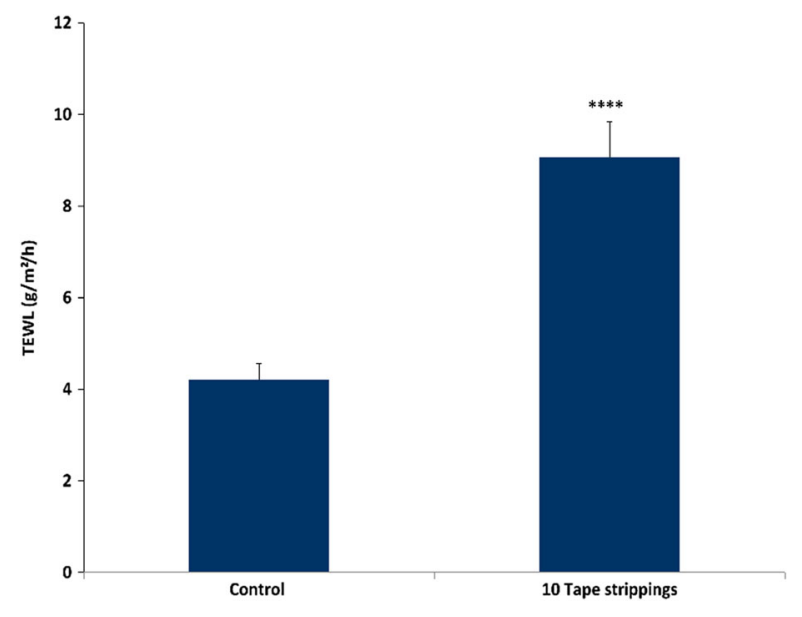

Fig. 1 Effect of 10 tape strippings on TEWL in ex vivo human skin. Data represent the mean and SEM $(n=9)$. Each condition was performed in triplicate on three different donors. ${ }^{* * * *} p<0.0001$ versus control

of the number of passages. On the other hand, TEWL was significantly lower $(p<0.05)$ following 6 or 8 passages of A-UN than following 10 tape strippings or 10 passages of A-UN. However, TEWL was not statistically different $(p>0.05)$ following 10 passages of A-UN or 10 tape strippings.

TEWL measurements following treatment with PR skin preparation pad demonstrated an increase in water efflux after 6 passages of PR compared to control untreated skin (2.14-fold; $8.98 \pm 0.63$ vs. $4.20 \pm 0.18 \mathrm{~g} / \mathrm{m}^{2} / \mathrm{h}$, respectively), 8 passages (2.70-fold; $11.34 \pm 1.23$ vs. $4.19 \pm 0.20 \mathrm{~g} / \mathrm{m}^{2} / \mathrm{h}$, respectively), and 10 passages (3.35-fold; $12.55 \pm 1.29$ vs. $3.75 \pm 0.24 \mathrm{~g} /$ $\mathrm{m}^{2} / \mathrm{h}$, respectively) (Fig. 3a). These data indicate that TEWL increased with the increasing number of passages of PR skin preparation pad.

Comparison analysis (Fig. 3b) showed that the difference between treated skin with PR skin preparation pad and untreated control skin was statistically significant $(p<0.05)$, regardless of the number of passages. On the other hand, TEWL was significantly higher $(p<0.05)$ following 8 or 10 passages of PR than following 10 tape strippings or 6 passages of PR. In addition, TEWL was significantly higher $(p<0.05)$ after 10 passages of PR than after 8 passages. However, TEWL was not statistically different $(p>0.05)$ following 6 passages of PR or 10 tape strippings.

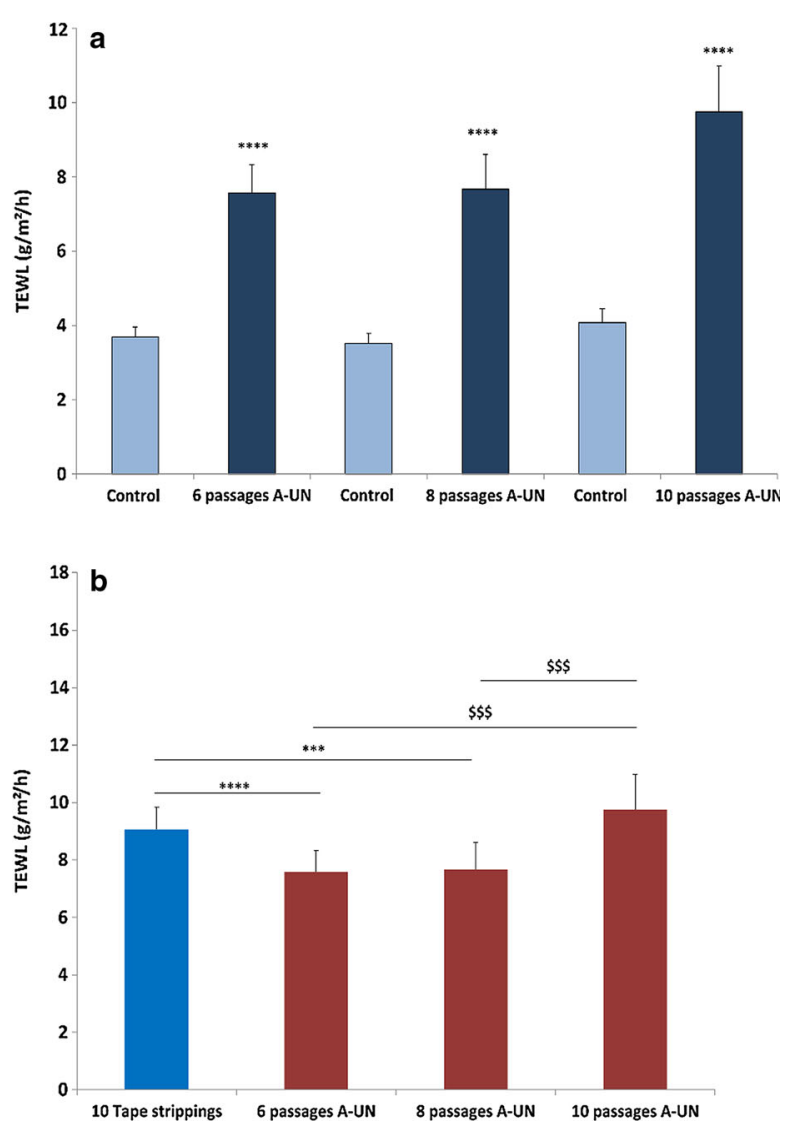

Fig. 2 Effect of the number of passages of Ambu Unilect $^{\mathrm{TM}}(A-U N)$ skin preparation pad on TEWL in ex vivo human skin. a TEWL was measured on intact skin (control) and after treatment of the same sample with A-UN. ${ }^{* * * *} p<0.0001$ versus control. b Comparison between the number of passages of A-UN and 10 tape strippings. ${ }^{* * *} p<0.001$ versus 10 tape strippings; ${ }^{* * * *} p<0.0001$ versus 10 tape strippings; $\$ \$ \$<0.001$ versus 10 passages of A-UN. Data represent the mean and SEM $(n=9)$. Each condition was performed in triplicate on three different donors

Comparison of both skin preparation pads showed that PR consistently induced significantly higher TEWL than A-UN $(p<0.05)$, regardless of the number of passages.

\section{Effect of Complete Removal of Epidermis on TEWL}

In order to demonstrate the magnitude of change that could be detected using this study model, the entire epidermis was mechanically 

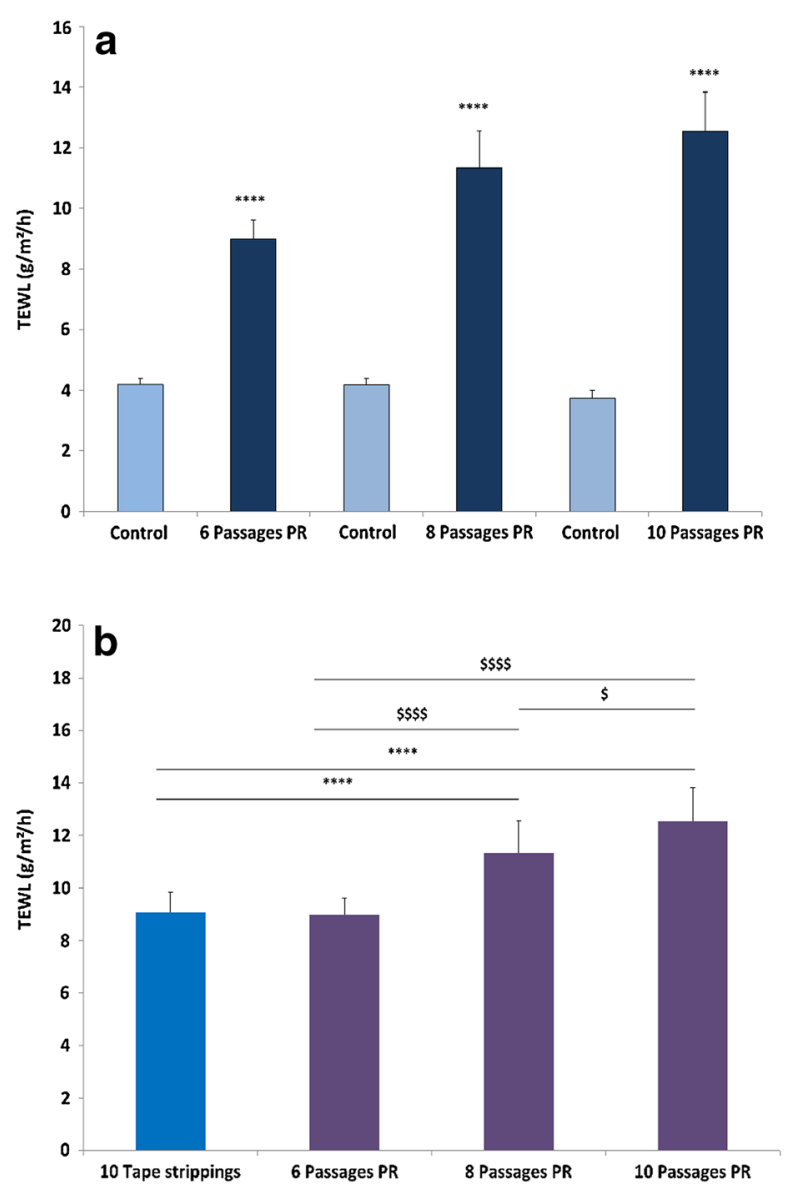

Fig. 3 Effect of the number of passages of PREPSTER ${ }^{\text {TM }}$ $(P R)$ skin preparation pad on TEWL in ex vivo human skin. a TEWL was measured on intact skin (control) and after treatment of the same sample with PR. ${ }^{* * * *} p<0.0001$ versus control. b Comparison between the number of passages of $\mathrm{PR}$ and 10 tape strippings. ${ }^{* * * *} p<0.0001$ versus 10 tape strippings; $\$ \$ \$ \$ 0.0001$ versus 10 passages of PR; ${ }^{\$} p<0.01$ versus 10 passages of PR. Data represent the mean and SEM $(n=9)$. Each condition was performed in triplicate on three different donors

removed. Complete removal of the epidermis increased TEWL compared to control (6.56-fold; $24.49 \pm 0.29$ vs. $3.73 \pm 0.18 \mathrm{~g} / \mathrm{m}^{2} /$ $\mathrm{h}$, respectively). Comparison analysis (Fig. 4) showed that the increase in TEWL following 10 tape strippings or 10 passages of either skin preparation pad was 2-fold to 3-fold lower than following complete removal of the epidermis and was statistically significant $(p<0.05)$.

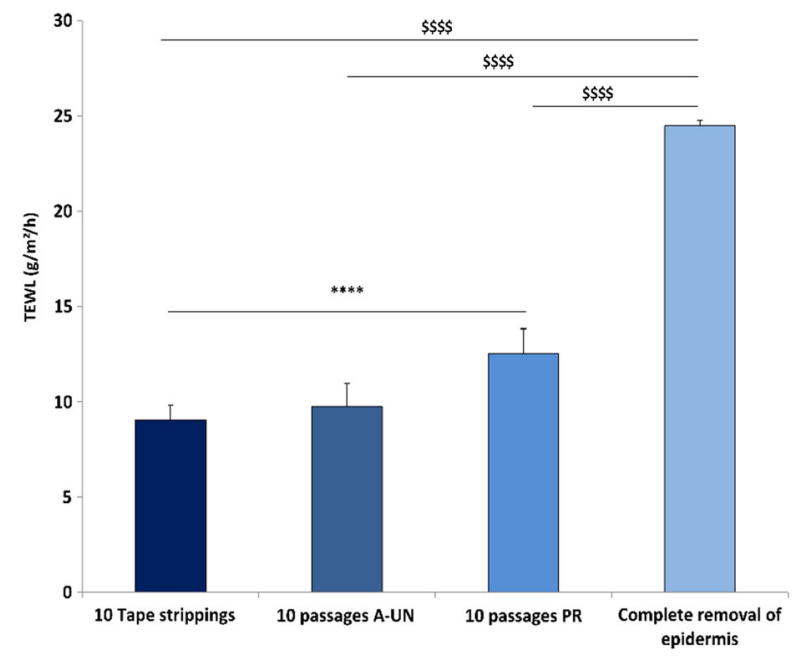

Fig. 4 Comparison of the effect of tape stripping, skin preparation pads [Ambu Unilect ${ }^{\mathrm{TM}}(A-U N)$ and PRE$\left.\operatorname{PSTER}^{\mathrm{TM}}(P R)\right]$, and complete removal of epidermis on TEWL in ex vivo human skin. Data represent the mean and SEM $(n=9)$. Each condition was performed in triplicate on three different donors, except for the complete removal of epidermis performed in triplicate on one donor $(n=3)$. ${ }^{* * * *} p<0.0001$ versus 10 tape strippings; $\quad \$ \$ \$ p<0.0001$ versus complete removal of epidermis

\section{Histological Analysis}

Histological analysis showed that the SC was only partially removed compared to control intact skin (Fig. 5a) following 10 tape strippings (Fig. 5b) or 10 passages of either A-UN (Fig. 5c) or PR (Fig. 5d), and that the epidermis was not damaged. Moreover, the complete removal of the epidermis was confirmed by skin section (Fig. 5e).

\section{DISCUSSION}

TEWL is one of the most commonly used parameters for the evaluation of skin barrier function. Numerous studies on TEWL have compared healthy and diseased skin, with a maximum of 10 or 20 tape strippings performed to mimic disrupted skin. In the current study, 10 tape strippings were used as a reference method to disrupt barrier function of the SC. 


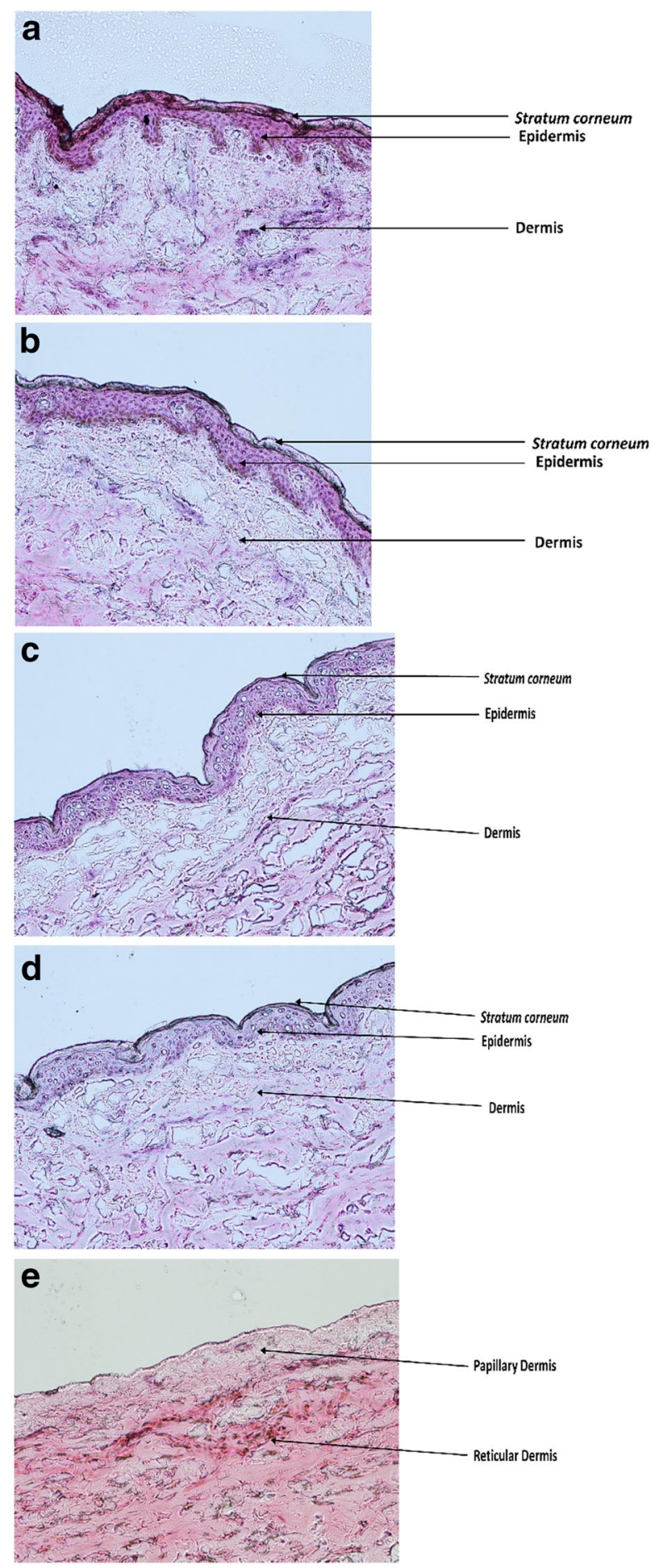

Fig. 5 Histological analysis of the effect of: a control, b tape stripping, c Ambu Unilect ${ }^{\mathrm{TM}}$ skin preparation pad, d PREPSTER ${ }^{\mathrm{TM}}$ skin preparation pad, and e complete removal of the epidermis in ex vivo skin
The results of the study showed a 2.4- and 3.3-fold increase in TEWL in ex vivo human skin following 10 passages of A-UN or PR skin preparation pads, respectively, indicating impairment of SC barrier properties. Moreover, TEWL increased with the increasing number of skin preparation pad passages. The increase in TEWL, reflecting impaired SC barrier function, depended on the skin preparation pad used. Ten passages of A-UN resulted in a similar increase in TEWL to 6 passages of PR, indicating that PR is more abrasive than A-UN.

Moreover, a 6.6-fold increase in TEWL was observed following the complete removal of the epidermis, indicating that samples with damaged membranes are unable to prevent water movement through the skin. The increase in TEWL following 10 tape strippings or 10 passages of a skin preparation pad was 2-fold to 3 -fold lower than that following complete removal of the epidermis. These findings confirm that tape stripping and skin abrasion using skin preparation pads impair the barrier function of skin samples only slightly.

The results of this study are consistent with published data showing that disruption of ex vivo porcine skin by either abrasion with an aluminum-coated sponge or tape stripping leads to an increase in TEWL. A 3-fold increase in TEWL was observed following 10 passages of the aluminum-coated sponge, resulting in increased total drug uptake of caffeine (7-fold), sorbic acid (4-fold) and testosterone (2-fold) [24]. Similarly, a 6-fold increase in TEWL was observed in ex vivo porcine skin after 10 tape strippings, leading to an increase in the total accumulated amount of betamethasone-17-valerate (4-fold) and fusidic acid (11-fold), respectively [25]. Moreover, other recent studies using ex vivo human skin have shown that MAL total penetration was increased by up to 103-fold after 10 passages of A-UN skin preparation-pad [26]. Therefore, a good correlation can be observed between increased TEWL reflecting impairment of skin barrier properties and increased uptake of MAL in ex vivo human skin.

In addition, numerous studies have suggested that high TEWL is associated with 
various skin diseases, including atopic dermatitis (abdominal site) (2.8-fold increase), psoriasis of the arm or shins (2.4-fold increase), and diaper dermatitis in infants (2.2-fold increase) [21-23]. The TEWL observed in the current study following 10 passages of skin preparation pads is approximately equivalent to that observed in the clinical setting. This indicates that, in addition to their use for the pre-treatment of skin prior to PDT, the two skin preparation pads investigated in this study may also be used as a new model to mimic diseased skin. Such models have previously been investigated using porcine skin [27]. This new model offers the possibility to adapt the number of passages of a skin preparation pad according to the therapeutic needs and the desired effect, targeting a pre-defined increase in TEWL.

Taken together, the findings presented in this article indicate that both PR and A-UN skin preparation pads may be successfully used for the pre-treatment of skin prior to PDT in order to enhance the uptake of MAL and improve treatment efficacy.

The major limitation of this study is that the skin samples were frozen and thawed. TEWL of normal fresh skin may be altered by freezing. Due to the difficulty in obtaining fresh skin samples at the precise time of experimentation, frozen human skin samples are typically used in permeability studies. The effect of the sample storage conditions on skin permeability remains controversial. Although, the effect of freezing on the metabolic activity of the skin is clear, the effect on the physical barrier properties of the skin is not well studied. In the current study, TEWL was measured on the same skin sample prior to and after impairment of the SC barrier function. It is conceivable that the magnitude of fold increase in TEWL may be different when using fresh skin, and may better reflect the in vivo condition.

\section{CONCLUSIONS}

Pre-treatment of skin using PREPSTER ${ }^{\mathrm{TM}}$ and Ambu Unilect ${ }^{\mathrm{TM}}$ skin preparation pads markedly increases TEWL, indicating slight impairment of the SC barrier function. Comparison of both skin preparation pads showed that the PREPSTER ${ }^{\mathrm{TM}}$ pad consistently induced significantly higher TEWL than the Ambu Unilect ${ }^{\mathrm{TM}}$ pad $(p<0.05)$, regardless of the number of passages. Both skin preparation pads are thought to increase the uptake of MAL and can therefore be used for the preparation of skin prior to PDT.

\section{ACKNOWLEDGEMENTS}

Sponsorship for this study and article processing charges were funded by Nestlé Skin Health Galderma R\&D. All authors had full access to all of the data in this study and take complete responsibility for the integrity of the data and accuracy of the data analysis. All named authors meet the International Committee of Medical Journal Editors (ICMJE) criteria for authorship for this manuscript, take responsibility for the integrity of the work as a whole, and have given final approval to the version to be published. Editorial assistance in the preparation of this manuscript was provided by S. P. Georgantopoulos, PhD, of SG Medical Writing B.V. Support for this assistance was funded by Nestlé Skin Health - Galderma R\&D.

Disclosures. Osman-Ponchet Hanan is an employee of Galderma R\&D. Gaborit Alexandre is an employee of Nestlé Skin Health - Galderma R\&D. Kouidhi Magali is an employee of Nestlé Skin Health - Galderma R\&D. Anglars Sandrine is an employee of Nestlé Skin Health Galderma R\&D. Marceau-Suissa Jeanne is an employee of Nestlé Skin Health - Galderma R\&D. Duffy-Roger Orla is an employee of Nestlé Skin Health - Galderma R\&D. Linget Jean-Michel is an employee of Nestlé Skin Health Galderma R\&D. Wilson Claire E. is an employee of Nestlé Skin Health - Galderma R\&D.

Compliance with Ethics Guidelines. This article does not contain any new studies with human or animal subjects performed by any of the authors. 
Data Availability. Data sharing is not applicable to this article as no datasets were generated or analyzed during the current study.

Open Access. This article is distributed under the terms of the Creative Commons Attribution-NonCommercial 4.0 International License (http://creativecommons.org/licenses/ by-nc/4.0/), which permits any noncommercial use, distribution, and reproduction in any medium, provided you give appropriate credit to the original author(s) and the source, provide a link to the Creative Commons license, and indicate if changes were made.

\section{REFERENCES}

1. Rubel DM, Spelman L, Murrell DF, et al. Daylight PDT with methyl aminolevulinate cream as a convenient, similarly effective, nearly painless alternative to conventional PDT in actinic keratosis treatment: a randomized controlled trial. Br J Dermatol. 2014;171:1164-71.

2. Lacour JP, Ulrich C, Gilaberte Y, et al. Daylight photodynamic therapy with methyl aminolevulinate cream is effective and nearly painless in treating actinic keratoses: a randomized, investigator-blinded, controlled, phase III study throughout Europe. J Eur Acad Dermatol Venereol. 2015;29:2342-8.

3. Morton CA, Szeimies RM, Sidoroff A, Braathen LR. European guidelines for topical photodynamic therapy part 1: treatment delivery and current indications-actinic keratoses, Bowen's disease, basal cell carcinoma. J Eur Acad Dermatol Venereol. 2013;27:536-44.

4. Szeimies RM, Lischner S, Philipp-Dormston W, et al. Photodynamic therapy for skin rejuvenation: treatment options - results of a consensus conference of an expert group for aesthetic photodynamic therapy. J Dtsch Dermatol Ges. 2013;11:632-6.

5. Spelman L, Holland T, Davidson K. Daylight-mediated photodynamic therapy for actinic keratosis-best practice guidelines. J Dermatol Nurs Assoc. 2016;8:265-8.

6. Wiegell SR, Haedersdal M, Philipsen PA, Eriksen P, Enk CD, Wulf HC. Continuous activation of PpIX by daylight is as effective as and less painful than conventional photodynamic therapy for actinic keratoses; a randomized, controlled, single-blinded study. Br J Dermatol. 2008;158:740-6.

7. Pariser DM, Lowe NJ, Stewart DM, et al. Photodynamic therapy with topical methyl aminolevulinate for actinic keratosis: results of a prospective randomized multicenter trial. J Am Acad Dermatol. 2003;48:227-32.

8. Wiegell SR, Fabricius S, Gniadecka M, et al. Daylight-mediated photodynamic therapy of moderate to thick actinic keratoses of the face and scalp: a randomized multicentre study. $\mathrm{Br} \mathrm{J}$ Dermatol. 2012;166:1327-32.

9. Wiegell SR, Haedersdal M, Eriksen P, Wulf HC. Photodynamic therapy of actinic keratoses with $8 \%$ and $16 \%$ methyl aminolaevulinate and home-based daylight exposure: a double-blinded randomized clinical trial. Br J Dermatol. 2009;160:1308-14.

10. Gerritsen MJP, Smits T, Kleinpenning MM, van de Kerkhof PCM, van Erp PEJ. Pretreatment to enhance protoporphyrin IX accumulation in photodynamic therapy. Dermatology. 2009;218:193-202.

11. Wiegell SR, Wulf HC, Szeimies RM, et al. Daylight photodynamic therapy for actinic keratosis: an international consensus. J Eur Acad Dermatol Venereol. 2012;26:673-9.

12. Morton C, Szeimies RM, Sidoroff A, et al. European Dermatology Forum Guidelines on topical photodynamic therapy. Eur J Dermatol. 2015;25:296-311.

13. See JA, Shumack S, Murrell DF, et al. Consensus recommendations on the use of daylight photodynamic therapy with methyl aminolevulinate cream for actinic keratoses in Australia. Australas J Dermatol. 2016;57:167-74.

14. Bay C, Lerche CM, Ferrick B, Philipsen PA, Togsverd-Bo $\mathrm{K}$, Haedersdal $\mathrm{M}$. Comparison of physical pretreatment regimens to enhance protoporphyrin IX uptake in photodynamic therapy: a randomized clinical trial. JAMA Dermatol. 2017;153:270-8.

15. Dickel H, Goulioumis A, Gambichler T, et al. Standardized tape stripping: a practical and reproducible protocol to uniformly reduce the stratum corneum. Skin Pharmacol Physiol. 2010;23:259-65.

16. Peppelman M, van den Eijnde WA, Jaspers EJ, Gerritsen MJ, van Erp PE. Combining tape stripping and non-invasive reflectance confocal microscopy: an in vivo model to study skin damage. Skin Res Technol. 2015;21:474-84.

17. Fritsch PO, Gschnait F, Kaaserer G, et al. PUVA suppresses the proliferative stimulus produced by stripping on hairless mice. J Invest Dermatol. 1979;73:188-90. 
18. Morgan CJ, Renwick AG, Friedmann PS. The role of stratum corneum and dermal microvascular perfusion in penetration and tissue levels of water-soluble drugs investigated by microdialysis. $\mathrm{Br} \mathrm{J}$ Dermatol. 2003;148:434-43.

19. Kottner J, Lichterfeld A, Blume-Peytavi U. Transepidermal water loss in young and aged healthy humans: a systematic review and meta-analysis. Arch Dermatol Res. 2013;305:315-23.

20. Herkenne C, Alberti I, Naik A, et al. In vivo methods for the assessment of topical drug bioavailability. Pharm Res. 2008;25:87-103.

21. Kim DW, Park JY, Na GY, Lee SJ, Lee WJ. Correlation of clinical features and skin barrier function in adolescent and adult patients with atopic dermatitis. Int J Dermatol. 2006;45:698-701.

22. Goon AT, Yosipovitch G, Chan YH, Goh CL. Barrier repair in chronic plaque-type psoriasis. Skin Res Technol. 2004;10:10-3.

23. Stamatas GN, Zerweck C, Grove G, Martin KM. Documentation of impaired epidermal barrier in mild and moderate diaper dermatitis in vivo using non-invasive methods. Pediatric Dermatol. 2011;28:99-107.

24. Schlupp P, Weber M, Schmidts T, Geiger K, Runkel F. Development and validation of an alternative disturbed skin model by mechanical abrasion to study drug penetration. Results Pharma Sci. 2014;4:26-33.

25. Simonsen L, Fullerton A. Development of an in vitro skin permeation model simulating atopic dermatitis skin for the evaluation of dermatological products. Skin Pharmacol Physiol. 2007;20:230-6.

26. Osman-Ponchet H, Gaborit A, Sevin K, et al. Skin preparation-pad abrasion, microneedling pretreatment or iontophoresis improves absorption of methyl aminolevulinate in ex vivo human skin. Photodiagn Photodyn Ther. 2017 (in press).

27. Davies DJ, Heylings JR, McCarthy TJ, Correa CM. Development of an in vitro model for studying the penetration of chemicals through compromised skin. Toxicol Vitro. 2015;29:176-81. 